\title{
Comparison of ISSR and SSR markers for analysis of genetic diversity in the seagrass Posidonia oceanica
}

\author{
Ilia Anna Serra ${ }^{1}$, Gabriele Procaccini ${ }^{2, *}$, Maria Carmela Intrieri ${ }^{3}$, \\ Marianna Migliaccio ${ }^{2}$, Silvia Mazzuca ${ }^{1}$, Anna Maria Innocenti ${ }^{1}$ \\ ${ }^{1}$ Dipartimento di Ecologia, Università della Calabria, 87036 Arcavacata di Rende, Cosenza, Italy \\ ${ }^{2}$ Stazione Zoologica 'A. Dohrn', Laboratorio di Ecologia del Benthos, 80077 Ischia, Napoli, Italy \\ ${ }^{3}$ Dipartimento di Biologia Animale e Genetica, Università di Firenze, 50125 Firenze, Italy
}

\begin{abstract}
Posidonia oceanica is an endemic seagrass species in the Mediterranean Sea. Due to its ecological importance, it has been the subject of several genetic studies aimed at increasing general knowledge of the system and helping to define appropriate management strategies. We compared the efficiency of 2 different classes of molecular markers, 'inter simple sequence repeats' (ISSRs) and 'simple sequence repeats' (SSRs) or 'microsatellites', in population genetic analysis of P. oceanica. To do this, we analyzed meadows along the coasts of the Calabria peninsula (Italy, South Tyrrhenian Sea and Ionian Sea), a putative biogeographic barrier for P. oceanica. SSR and ISSR markers detected different levels of genetic variability within $P$. oceanica populations. Dinucleotide microsatellites were more polymorphic than tri- and heptanucleotide microsatellites and ISSRs. Nevertheless, discriminating power analysis performed for each single locus showed that some trinucleotide microsatellite and ISSR primers were more sensitive than dinucleotides. The use of selected ISSR and SSR markers together allowed the detection of higher polymorphism than either set of marker alone. Tyrrhenian meadows were always more polymorphic than Ionian ones, according to both SSRs and ISSRs. Both markers strongly suggested the Calabria peninsula as an important biogeographic barrier between the Western and the Eastern side of the Mediterranean basin.
\end{abstract}

KEY WORDS: Posidonia oceanica $\cdot$ ISSR $\cdot$ SSR $\cdot$ Genetic diversity $\cdot$ Biogeographic barrier Resale or republication not permitted without written consent of the publisher

\section{INTRODUCTION}

Marine flowering plants or seagrasses are distributed worldwide and play an important role in the dynamics and stabilization of the coastline (Procaccini et al. 2003). Seagrasses reproduce sexually, through hydrophilous pollination, and vegetatively by elongation of subterranean rhizomes bearing new leaf shoots (Den Hartog 1970). These factors combine to make identification of individuals problematic, requiring the use of high-resolution molecular markers to assign single shoots (ramets) to separate genets (Reusch 2001, Waycott et al. 2006).
A number of markers are currently available which can discriminate among ramets in such instances (Procaccini \& Maltagliati 2004). Among these, 'simple sequence repeats' (SSRs; Jarne \& Lagoda 1996) or 'microsatellites' have been successful in population genetic studies of benthic organisms in general, due to their high variability and statistical power (Reusch 2001). SSRs are co-dominantly inherited, allowing the heterozygote in diploid genomes to be distinguished. SSRs are highly reproducible thanks to specific PCR amplifications of short repeated sequences, which produce polymorphic patterns depending on the number of repeated units (Goldstein \& Schlotterer 1999). Their 
initial cost of development is relatively high but, once the loci are selected, the method becomes fast and readily employed (Jarne \& Lagoda 1996, Goulão \& Oliveira 2001). Limited statistical analysis and poor cross-experimental reproducibility represent some drawbacks of dominant markers, where the homozygous presence of a fragment is not distinguishable from its heterozygote. Among dominant markers, 'inter simple sequence repeats' (ISSR; Zietkiewitcz et al. 1994) are more reproducible than 'random amplified polymorphic DNA' (RAPD; Williams et al. 1990) and less expensive to use than 'amplified fragment length polymorphism' (AFLP; Vos et al. 1995). ISSR markers use arbitrary primers represented by short repeated sequences. Allelic polymorphisms occur whenever the repeated sequence is missing or insertions/deletions modify the distance between repeats. ISSRs have the advantage of allowing analysis of multiple loci in a single reaction and to be more accessible to ecological laboratories that lack sophisticated equipment and/or adequate technical expertise. ISSRs have been applied successfully in population genetic studies for a variety of organisms, including clonal plants (King et al. 2002, Wang et al. 2004).

Posidonia oceanica (L.) Delile is an endemic Mediterranean seagrass, widely distributed along the Mediterranean coasts where it forms large monospecific beds across a wide bathymetric gradient (Procaccini et al. 2003). P. oceanica meadows fulfil important ecological functions, stabilising the substratum, attenuating wave action, increasing oxygen in nearshore waters and sheltering juveniles of fishes and invertebrates (Procaccini et al. 2003). P. oceanica has a monoecious mating system and potentially long-range dispersal by floating fruits and detached vegetative fragments. Sexual reproduction occurs irregularly throughout the whole basin and very large clones, extending over more than $100 \mathrm{~m}$, can be found within the meadows (Migliaccio et al. 2005). P. oceanica meadows, like other seagrass ecosystems, are extremely sensitive to the moderate to high levels of disturbances often associated with highly human impacted coasts (Procaccini et al. 2003).

Due to its ecological importance and to the strong human impact along the coast of the Mediterranean basin, Posidonia oceanica has been the object of several genetic studies (Procaccini et al. 2001, 2002, Arnaud-Haond et al. 2005, 2007). These studies aimed to increase general knowledge of the system and to support coastal management and restoration programs. P. oceanica meadows exhibit different levels of genetic variability when investigated with different molecular markers. Initial studies using allozymes (Capiomont et al. 1996) and multilocus DNA markers such as randomly amplified polymorphic DNA (RAPD) and M13-DNA fingerprinting (Procaccini et al. 1996) indicated that meadows were almost completely clonal and highly distinct genetically. More recent studies using more RAPD primers (Jover et al. 2003, Micheli et al. 2005) and tri- and heptanucleotide microsatellites (SSRs; Procaccini et al. 2001, 2002), contradicted these findings detecting higher levels of variation. This is not surprising for allozymes (i.e. electrophoretically separable morphs of enzymes) if we consider that they cannot take into consideration silent mutations in coding and non-coding regions of DNA and, therefore, they underestimate the real genetic variation. With multilocus DNA fingerprinting techniques, instead, polymorphism can be wiped out from the analysis together with faint or not well represented bands in replicated electrophoretic profiles. Recent and significant advances in population genetics of $P$. oceanica have been made possible by the selection of highly polymorphic dinucleotide microsatellites (Alberto et al. 2003). Data obtained with those markers changed the perception of $P$. oceanica as a species with low genetic variability by detecting, at least in some localities, very high levels of genetic diversity (Arnaud-Haond et al. 2005, 2007, Migliaccio et al. 2005).

We are aware that advanced and expensive molecular analyses, such as microsatellite genotyping, are not easily performed in an ecological laboratory. The aim of this paper was to evaluate the resolution of ISSR markers with respect to their use for studying genetic diversity and gene flow in Posidonia oceanica in comparison with other molecular markers, especially SSRs. We used SSR and ISSR markers to analyze genetic diversity among populations of Posidonia oceanica along the Calabrian coasts (Italy, South Tyrrhenian Sea and Ionian Sea), a region from which no previous genetic data for $P$. oceanica meadows exist.

\section{MATERIALS AND METHODS}

Plant material and DNA extraction. Individual shoots of Posidonia oceanica (L.) Delile were randomly sampled by SCUBA diving from 5 populations along the coast of Calabria, Italy (Fig. 1): 3 in the Tyrrhenian Sea (Praia a Mare, San Nicola Arcella, Belmonte Calabro) and 2 in the Ionian Sea (Crotone, Cariati).

About 25 individual shoots were collected from each meadow. Shoots were collected every 8 to $10 \mathrm{~m}$ along linear transects, to minimize the risk of sampling within the same clonal patch. Samples were transferred to the laboratory, cleaned of epiphytes with a razor blade and stored at $-80^{\circ} \mathrm{C}$ for DNA extraction.

DNA was purified according to Doyle \& Doyle (1987) and modified as following: ca. $100 \mathrm{mg}$ wet weight of leaf tissue were ground to a fine powder in a mortar 


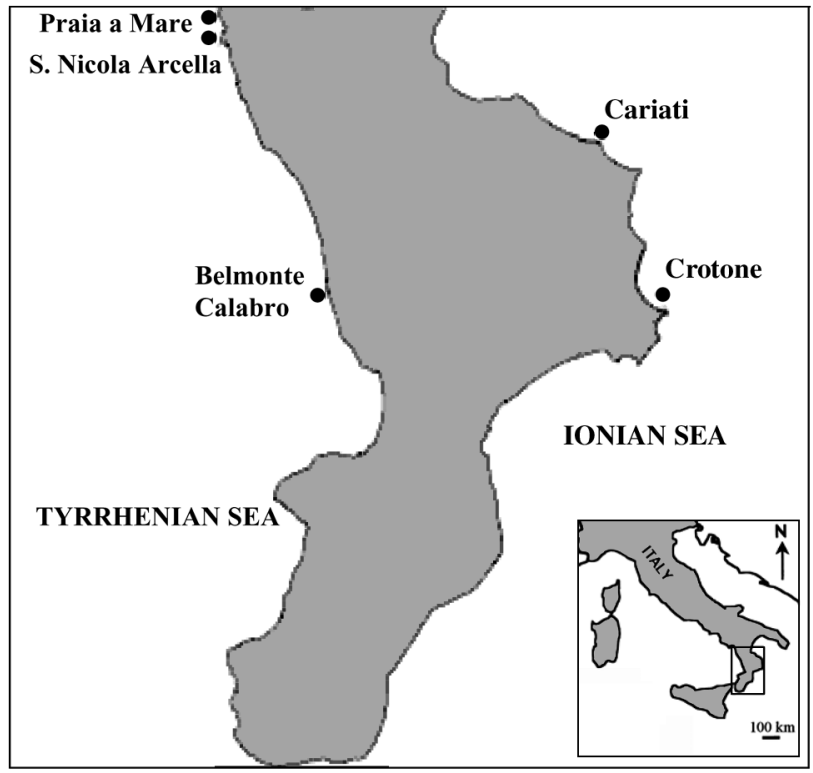

Fig. 1. Map of the Calabria peninsula showing locations of sampling sites: Praia a Mare $\left(39^{\circ} 54^{\prime} \mathrm{N}, 15^{\circ} 45^{\prime} \mathrm{E}\right)$, San Nicola

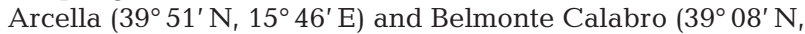
$\left.16^{\circ} 03^{\prime} \mathrm{E}\right)$ in the Tyrrhenian Sea; Crotone $\left(39^{\circ} 03^{\prime} \mathrm{N}, 17^{\circ} 08^{\prime} \mathrm{E}\right)$ and Cariati $\left(39^{\circ} 30^{\prime} \mathrm{N}, 16^{\circ} 57^{\prime} \mathrm{E}\right)$ in the Ionian Sea

using liquid nitrogen and then transferred to a 1.5 Eppendorf tube filled with the extraction buffer $(2 \%$ CTAB, 2\% 2-mercaptoethanol, 1.4 M NaCl, $20 \mathrm{mM}$ EDTA, $200 \mathrm{mM}$ Tris- $\mathrm{HCl} \mathrm{pH}$ 7.5). After incubation at $60^{\circ} \mathrm{C}$ for $30 \mathrm{~min}$ the homogenate was washed once with $800 \mu \mathrm{l}$ chloroform-isoamyl alcohol (24:1 v/v) and precipitated with an equal volume of ice-cold isopropanol. The DNA pellet was washed twice, first with $100 \mu \mathrm{l}$ of Buffer A (76\% EtOH, 200 mM sodiumacetate) and then with $100 \mu \mathrm{l}$ of Buffer B (76\% EtOH, $10 \mathrm{mM}$ ammonium-acetate), air-dried and dissolved in $100 \mu \mathrm{l}$ of TE buffer $(10 \mathrm{mM}$ Tris- $\mathrm{HCl}, 1 \mathrm{mM}$ EDTA, $\mathrm{pH}$ 8). RNA was removed by incubating at $37^{\circ} \mathrm{C}$ for 60 min with RNase A $\left(0.1 \mu \mathrm{g} \mathrm{ll}^{-1}\right)$. Total genomic DNA was quantified using a DyNA QuantTM 200 fluorometer (Hoefer) and working solutions $\left(25 \mathrm{ng} \mathrm{ul}^{-1}\right)$ were prepared in sterile water.

ISSR analysis. A total of twelve 3 '-anchored primers (MWG-Biotech) were tested for ISSR amplifications in Posidonia oceanica (Table 1). Eight primers that showed clear and reproducible banding patterns were selected. The 8 primers include 10 di-nucleotide repeats and 2 tri-nucleotide repeats. Amplification reactions were carried out in $25 \mu$ l volumes containing $37.5 \mathrm{ng}$ of template DNA, 1 unit of Taq-polymerase

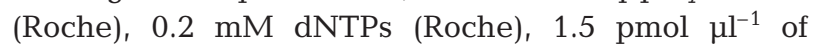
primer (MWG-Biotech), $10 \mathrm{mM}$ Tris-HCl (pH 8.3) and $1.5 \mathrm{mM} \mathrm{MgCl}_{2}, 50 \mathrm{mM} \mathrm{KCl}$. PCR reactions were performed under the following conditions: $3 \mathrm{~min}$ at $94^{\circ} \mathrm{C}$
Table 1. Nucleotide sequences of 12 primers tested for ISSRPCR in Posidonia oceanica. * Primers utilized in the analysis

\begin{tabular}{|c|c|}
\hline Name & Sequence \\
\hline ISSR1 & 5'-СТСТСТСТСТСТСТСТYС-3' \\
\hline ISSR2* & 5'-СТCTCTCTCTCTCTCTRG-3' \\
\hline ISSR ${ }^{*}$ & 5'-GTGTGTGTGTGTYR-3' \\
\hline ISSR4 & 5'-GTGTGTGTGTGTAY-3' \\
\hline ISSR5* & 5'-CACACACACACARY-3' \\
\hline ISSR6* & 5'-CACACACACACACAYC-3' \\
\hline ISSR7 $^{*}$ & 5'-AGAGAGAGAGAGAGYC-3' \\
\hline ISSR8* & 5'-GAGAGAGAGAGAGARG-3' \\
\hline ISSR9 & 5'-ATATATATATATATATGG-3' \\
\hline ISSR10* & 5'-CTCCTCCTCCTCRC-3' \\
\hline ISSR11* & 5'-GAGGAGGAGGAGRC-3' \\
\hline ISSR12 & 5'-TATATATATATATATACC-3' \\
\hline
\end{tabular}

for initial denaturation, 35 cycles of $60 \mathrm{~s}$ at $94^{\circ} \mathrm{C}$ (denaturation), $60 \mathrm{~s}$ at $44^{\circ} \mathrm{C}$ (annealing), and $90 \mathrm{~s}$ at $72^{\circ} \mathrm{C}$ (extension), followed by a final extension of $5 \mathrm{~min}$ at $72^{\circ} \mathrm{C}$ for final extension.

PCR products were separated on $2.5 \%$ Agarose $0.5 \mathrm{X}$ TBE gels, ethidium-bromide stained and visualized on a UV light box. Photographs were taken of each gel using a Polaroid camera (DS-34). A 100 base-pair ladder was used to estimate the molecular size of bands.

ISSR reactions were repeated at least 3 times and bands that were not consistent in all 3 reactions were discarded. Although a very high number of larger fragments existed, the proximity between bands or their low intensity made scoring very difficult. Highly reproducible bands uniformly comprised 300 to $1500 \mathrm{bp}$ fragments. Bands within the selected size-range were also discarded when they were overlapping or unclear. ISSR bands were scored as absent (0) and present (1), assuming that each band position corresponded to 1 'locus' with 2 'alleles' respectively. The final data sets included both polymorphic and monomorphic fragments.

SSR analysis. Thirteen polymorphic microsatellite regions, 12 nuclear and 1 chloroplastic, were used to obtain individual multilocus genotypes. We refer to the 6 loci previously isolated by Procaccini \& Waycott (1998), with a dominance of trinucleotide repeats, as T-SSR. The 7 loci isolated by Alberto et al. (2003), with a dominance of dinucleotide repeats, are referred to D-SSR (Table 2). Reactions were carried out in a total volume of $10 \mu \mathrm{l}$ following Migliaccio et al. (2005). PCR amplifications were checked on 1.5\% Agarose 1X TAE gels.

SSR allele detection was conducted using an automated sequencer (CEQ 2000XL DNA Analysis system, Beckman Coulter) and electropherograms were analysed using the Beckman CEQ 2000 ver. 3.0 software (Beckman Coulter). 
Table 2. Polymorphism of ISSR and SSR (T-SSR and D-SSR) markers. Molecular Variants (MVs) are represented by bands in ISSR and alleles in SSR. $C$ : confusion probability; $D$ : discriminating power; $D_{L}$ : limit of discriminating power; $D$ class: order in the score of $D$

\begin{tabular}{|c|c|c|c|c|c|c|c|}
\hline Marker & $\begin{array}{c}\text { Number of } \\
\text { MVs }\end{array}$ & $\begin{array}{c}\text { Number of } \\
\text { polymorphic MVs }\end{array}$ & $\begin{array}{l}\text { Number of } \\
\text { patterns }\end{array}$ & $C$ & $D$ & $D_{L}$ & $D$ class \\
\hline \multicolumn{8}{|l|}{ ISSR } \\
\hline ISSR2 & 7 & 2 & 3 & 0.423 & 0.577 & 0.575 & 9 \\
\hline ISSR3 & 8 & 2 & 3 & 0.549 & 0.451 & 0.447 & 12 \\
\hline ISSR5 & 16 & 2 & 4 & 0.507 & 0.493 & 0.489 & 11 \\
\hline ISSR6 & 9 & 0 & 1 & - & - & - & - \\
\hline ISSR7 & 12 & 0 & 1 & - & - & - & - \\
\hline ISSR8 & 8 & 1 & 2 & 0.807 & 0.193 & 0.192 & 16 \\
\hline ISSR10 & 10 & 3 & 6 & 0.384 & 0.616 & 0.616 & 6 \\
\hline \multirow[t]{2}{*}{ ISSR11 } & 5 & 0 & 1 & - & - & - & - \\
\hline & & & Mean values & 0.534 & 0.466 & 0.464 & \\
\hline \multicolumn{8}{|l|}{ T-SSR ${ }^{a}$} \\
\hline Poc-trn & 2 & 2 & 2 & 0.983 & 0.017 & 0.017 & 18 \\
\hline Poc-42 & 2 & 2 & 3 & 0.438 & 0.562 & 0.558 & 10 \\
\hline Poc-5 & 3 & 3 & 4 & 0.566 & 0.434 & 0.441 & 13 \\
\hline$P o C-45$ & 6 & 6 & 10 & 0.311 & 0.689 & 0.683 & 5 \\
\hline$P o C-35$ & 5 & 5 & 11 & 0.145 & 0.855 & 0.848 & 3 \\
\hline \multirow[t]{2}{*}{ Poc-26 } & 3 & 3 & 3 & 0.656 & 0.344 & 0.341 & 15 \\
\hline & & & Mean values & 0.516 & 0.484 & 0.481 & \\
\hline \multicolumn{8}{|l|}{ D-SSR ${ }^{b}$} \\
\hline Po5-39 & 3 & 3 & 4 & 0.635 & 0.365 & 0.362 & 14 \\
\hline Po5-10 & 4 & 4 & 7 & 0.389 & 0.611 & 0.674 & 8 \\
\hline Po5 & 4 & 4 & 7 & 0.373 & 0.627 & 0.697 & 7 \\
\hline Рo-15 & 8 & 8 & 18 & 0.093 & 0.907 & 0.903 & 2 \\
\hline Po5-40 & 15 & 15 & 24 & 0.076 & 0.924 & 0.918 & 1 \\
\hline Po5-49 & 7 & 7 & 12 & 0.167 & 0.831 & 0.853 & 4 \\
\hline \multirow[t]{2}{*}{ Po4-3 } & 3 & 3 & 3 & 0.889 & 0.111 & 0.110 & 17 \\
\hline & & & Mean values & 0.375 & 0.625 & 0.645 & \\
\hline \multicolumn{8}{|c|}{ aProcaccini \& Waycott (1998) } \\
\hline${ }^{\mathrm{b}}$ Alberto & 2003) & & & & & & \\
\hline
\end{tabular}

Data analysis. To compare the efficiency of ISSR, D-SSR and T-SSR markers, we estimated the following parameters as described in Tessier et al. (1999): (1) number of polymorphic molecular variants (MV are represented by bands for ISSR and alleles for SSR markers); (2) number of banding patterns for each SSR locus/ISSR primer; (3) confusion probability $(C j)$ of $j$ th assay unit:

$$
C j=\sum_{i=1}^{I} p_{i}\left[\left(N p_{i}-1\right) /(N-1)\right]
$$

where $p_{i}$ is the frequency of the $i$ th pattern, $N$ the sample size and $I$ the total number of patterns generated by the $j$ th assay unit; (4) discriminating power $(D j)$ of the $j$ th assay unit:

$$
D j=1-C j
$$

(5) limit of $D j$ as $N$ tends towards infinity

$$
D_{L}=\lim (D j)=1-\sum_{i=1}^{I} p_{i}^{2}
$$

Clonal diversity was calculated in each population (for each marker) as the proportion of distinguishable genets $(G / N)$, where $G$ is the number of genets detected and $N$ is the number of samples (Pleasant \& Wendel 1989). In order to find the best possible marker combination to use for assessing intra-population variability we plotted $G / N$ values obtained by adding sequentially one marker at a time starting with the one having the highest $D$ value. Only SSR markers with the highest $9 D$ values and ISSR markers with the highest $2 D$ values were considered. Curves describing the dependence of $G / N$ on number of markers were compared.

In order to evaluate how efficiently the different markers performed in partitioning molecular variance, an AMOVA was carried out using the software GenAlEx 6 (Peakall \& Smouse 2006). Variation was expressed both as the proportion of the total variance and as $\Phi$-statistics, an $F$-statistic analogue, where $\Phi_{\mathrm{rt}}$ represents the correlation of individuals from the same geographic region relative to that of individuals from the whole data set, $\Phi_{\mathrm{pr}}$ represents the correlation between individuals within a population relative to that of individuals from the same geographic region and $\Phi_{\text {pt }}$ represents the correlation between individuals within a population relative to that of individuals from the whole data set. Estimates of $\Phi_{\mathrm{pt}}$ values were also obtained to assess gene flow within and between geographic regions. Significance was tested by random permutation, with the number of permutations set to 9999. 
Principal coordinates analysis (PCA) calculated on pairwise genetic distance for both the ISSR and SSR data sets was performed using GenAlEx 6 software (Peakall \& Smouse 2006). Distances were calculated as in Huff et al. (1993) for ISSRs and as in Peakall et al. (1995) for SSR data. Nei's (1978) genetic distance (Nm) was calculated using POPGENE software (Yeh et al. 1997). Dendrograms based on Nei's (1978) genetic distance and the UPGMA trees were also constructed using POPGENE.

\section{RESULTS}

Of the 12 primers tested for ISSR analysis, only 8 were selected for final scoring and only 5 of them were polymorphic. The sizes of alleles for SSR loci were within the expected range based on published data (Procaccini et al. 2001, Arnaud-Haond et al. 2005, 2007, Migliaccio et al. 2005).

In order to evaluate relative polymorphism among the different markers classes utilized, we compared data obtained from SSR alleles with those from ISSR bands. The total number of molecular variants (MVs) varies from 75 for ISSR to 21 for T-SSR (Table 2). All MVs were polymorphic both for D-SSR and for T-SSR data; however, only $13.3 \%$ were polymorphic among the ISSR bands. The value slightly increased $(20.4 \%)$ when only the polymorphic ISSR primers were considered (Table 2).

Discriminating power was lower for polymorphic ISSR (mean $D=0.466$ ) than for T-SSRs and D-SSRs, respectively (mean $D=0.484$ and 0.625 , Table 2 ). Confusion probability values showed the opposite trend, with higher mean values for ISSRs and lower mean values for SSR (Table 2). With respect to the discriminating power of single ISSR-primers/SSR-loci, the values were not always coherent within the same marker class. For example, T-SSR loci $P O C-35$ and $P O C-45$ were the third and fifth most powerful loci, respectively; ISSR10 was 6th; D-SSR loci Po5-39 and Po4-3 were in 14th and 17th position, respectively, across all 18 polymorphic markers (Table 2).

Tyrrhenian populations were more polymorphic than Ionian ones, both in terms of number of $\mathrm{G} / \mathrm{N}$ values and of MVs (Table 3). The number of polymorphic ISSR bands ranged from 1 in the 2 Ionian populations to 9 in Praia, where a higher number of SSR alleles was also found (Table 3).

Overall, D-SSR markers detected higher clonal diversity $(G / N=0.50$,
Table 3), with the value increasing to 0.64 for all SSR markers collectively. Clonal diversity values for ISSR markers varied widely among the 5 populations considered, ranging from 0.91 in Praia to 0.08 in the 2 Ionian populations. Tyrrhenian populations were more diverse than Ionian ones as indicated by microsatellite markers (Table 3). Interestingly, multilocus genotypes based on combined SSR and ISSR markers resulted in higher values of clonal diversity. Overall $G / N$ values increased from 0.44 (ISSRs) and 0.64 (SSRs) to 0.75 (all markers combined; Table 3).

By comparing curves obtained by plotting $G / N$ values of marker combinations against the 9 SSRs and 2 ISSRs with highest $D$ values (Table 2, Fig. 2) it is evident that $G / N$ values reach saturation after 5 loci in the 2 less polymorphic populations (Crotone and Cariati). In the other populations, $G / N$ values increase up to the addition of the last SSR locus and saturate only after the addition of ISSR10 and ISSR2 to the first 9 SSR loci (Fig. 2).

The different classes of molecular markers also vary in their ability to distinguish populations and quantify gene flow. All marker categories evaluated and all indices calculated showed limited gene flow between the 2 geographic regions as evidenced by the low $\mathrm{Nm}$ and high $\Phi_{\mathrm{pt}}$ values in the last column of Table 4 . Higher distinction was achieved by SSR markers (SSR $\Phi_{\mathrm{pt}}=0.596 ;$ ISSR $\Phi_{\mathrm{pt}}=0.584 ;$ Table 4). Very low genetic distance and high gene flow are detected by ISSR markers between the 2 Ionian populations, as showed by the high $N m$ value and low $\Phi_{\mathrm{pt}}$ value in the 'Ionian' column of Table 4, where SSR, instead, show higher resolution. This relationship is also clear in the PCA plots (Fig. 3). Distinction between Tyrrhenian and Ionian regions is also evident in the Tot-SSR plot (Fig. 3b), where the 2 Ionian populations (Cariati, Crotone) are clearly differentiated from the others. However, for the Tyrrhenian populations, Praia individuals are partially

Table 3. G/N values and polymorphic Molecular Variants (MV) for populations and population groups. Molecular Variants are represented by bands in ISSR and alleles in SSR. Ty: Tyrrhenian Sea; Io: Ionian Sea; T-SSR and D-SSR, see Table 1; Tot-SSR: total number of microsatellite markers; All markers: ISSR+SSR markers

\begin{tabular}{|c|c|c|c|c|c|c|c|c|c|c|}
\hline $\begin{array}{l}\text { Populations/ } \\
\text { Geographic areas }\end{array}$ & \multicolumn{2}{|c|}{$\begin{array}{c}\text { ISSR } \\
\text { G/N MV }\end{array}$} & \multicolumn{2}{|c|}{$\begin{array}{l}\text { D-SSR } \\
G / N \text { MV }\end{array}$} & \multicolumn{2}{|c|}{$\begin{array}{c}\text { T-SSR } \\
\text { G/N MV }\end{array}$} & \multicolumn{2}{|c|}{$\begin{array}{l}\text { Tot-SSR } \\
\text { G/N MV }\end{array}$} & \multicolumn{2}{|c|}{$\begin{array}{c}\text { All markers } \\
\text { G/N MV }\end{array}$} \\
\hline Praia (Ty) & 0.91 & 9 & 0.50 & 26 & 0.50 & 14 & 0.68 & 40 & 0.95 & 49 \\
\hline San Nicola (Ty) & 0.67 & 7 & 0.62 & 23 & 0.42 & 15 & 0.71 & 38 & 0.96 & 45 \\
\hline Belmonte (Ty) & 0.64 & 8 & 0.52 & 25 & 0.44 & 15 & 0.72 & 40 & 0.92 & 48 \\
\hline Crotone (Io) & 0.08 & 1 & 0.48 & 19 & 0.40 & 12 & 0.60 & 31 & 0.60 & 32 \\
\hline Cariati (Io) & 0.08 & 1 & 0.36 & 15 & 0.28 & 11 & 0.47 & 26 & 0.47 & 27 \\
\hline Tyrrhenian Sea & 0.70 & 10 & 0.55 & 36 & 0.45 & 17 & 0.70 & 53 & 0.94 & 63 \\
\hline Ionian Sea & 0.06 & 2 & 0.42 & 23 & 0.34 & 14 & 0.54 & 37 & 0.52 & 39 \\
\hline Overall & 0.44 & 10 & 0.50 & 44 & 0.40 & 21 & 0.64 & 65 & 0.75 & 75 \\
\hline
\end{tabular}




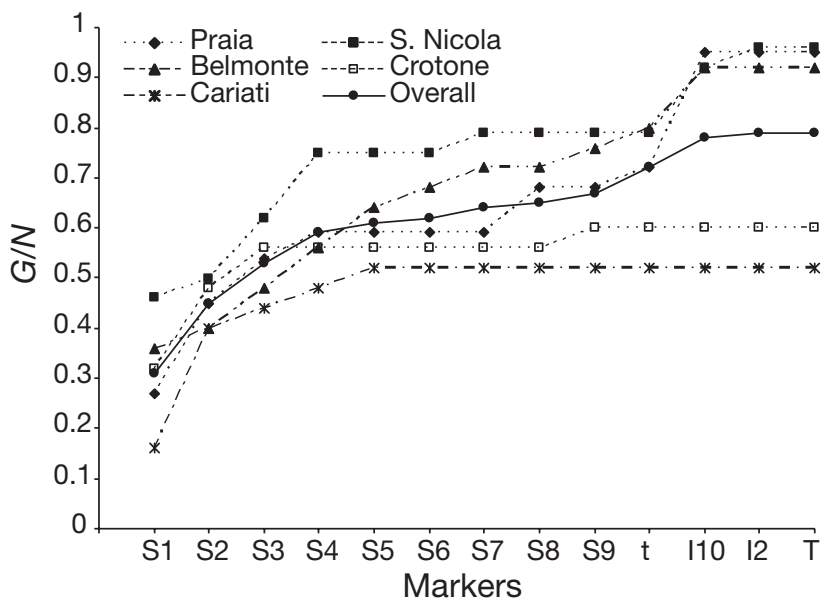

Fig. 2. Values of clonal diversity $(G / N)$ per population and overall, obtained by adding sequentially the SSR loci with the first 9 scores (D-class) and the ISSR primers with the first 2 scores in Table 2. S1 = Po5-40; S2 = Po5-40 + Po-15; S3 = Po5$40+$ Po-15 + Poc-35; etc.; t: total SSR loci; I10 = S9 + ISSR10; $\mathrm{I} 2=\mathrm{S} 9+\mathrm{ISSR} 10+\mathrm{ISSR} 2 ; \mathrm{T}=\mathrm{SSR}+\mathrm{ISSR}$

Table 4. Measures of genetic distance (Dist) and gene flow $\left(\Phi_{\mathrm{pt}}\right.$ $\mathrm{Nm}$ ) within and between population groups. Dist $=$ Nei's (1978) genetic distance; $\mathrm{Nm}=0.25 \times\left(1-\Phi_{\mathrm{pt}}\right) / \Phi_{\mathrm{pt}} \cdot{ }^{*} \mathrm{p}=0.022$ for ISSR markers, otherwise $p<0.001$

\begin{tabular}{|llllc|}
\hline \multirow{7}{*}{ ISSR } & & Tyrrhenian & Ionian & $\begin{array}{c}\text { Tyrrhenian } \\
\text { vs. Ionian }\end{array}$ \\
& & & & 0.037 \\
& Dist & 0.021 & 0.004 & 0.584 \\
& $\Phi_{\mathrm{pt}}$ & 0.253 & $0.131^{*}$ & 0.177 \\
& $\mathrm{Nm}$ & 0.739 & 1.658 & 0.179 \\
& $\mathrm{Dist}$ & 0.257 & 0.204 & 0.524 \\
& $\Phi_{\mathrm{pt}}$ & 0.369 & 0.498 & 0.589 \\
& $\mathrm{Nm}$ & 0.428 & 0.252 & 0.174 \\
Tot-SSR & $\mathrm{Dist}$ & 0.116 & 0.200 & 0.318 \\
& $\Phi_{\mathrm{pt}}$ & 0.354 & 0.532 & 0.582 \\
& $\mathrm{Nm}$ & 0.455 & 0.219 & 0.179 \\
& $\mathrm{Dist}$ & 0.179 & 0.203 & 0.407 \\
& $\Phi_{\mathrm{pt}}$ & 0.366 & 0.514 & 0.596 \\
& $\mathrm{Nm}$ & 0.434 & 0.236 & 0.169 \\
\hline
\end{tabular}

intermixed with those from San Nicola and Belmonte. Population clusters are less confined in the ISSR plot (Fig. 3a), where the distinction between the 2 regions is less obvious.

In all cases the dendrograms based on Nei's genetic distance showed identical clustering relationships among all populations. The position of the 3 western populations (Praia, Belmonte, San Nicola) within the cluster was identical and consistent with their geographic position. The 2 closest populations (Praia, San Nicola) always clustered together. The relative poorer ability of ISSR markers to separate the 2 Ionian populations (Cariati, Crotone) was indicated by the low extent of genetic distance separating these accessions in the ISSR dendrogram (Fig. 4).
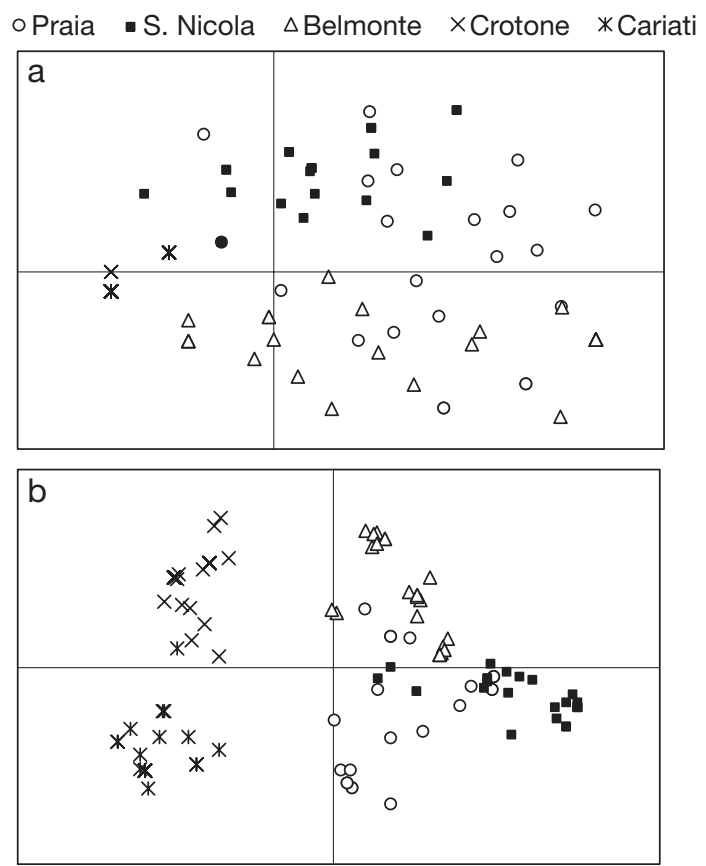

Fig. 3. PCA plots of the first 2 axes based on (a) individual ISSR and (b) SSR distance matrices

AMOVA showed a higher percent variance among individuals within populations with all marker classes (Table 5). Values of variance among populations within regions were low as determined by ISSR markers (variance $=0.396$ ), due to the Ionian populations. Tot-SSRs showed consistently higher variance between the 2 regions with respect to ISSR markers (Table 5).

\section{DISCUSSION}

The goal of our analysis was to compare the efficiency of 2 different classes of molecular markers (ISSRs and SSRs) in population genetic analyses of Posidonia oceanica, a clonal marine macrophyte. Our results suggest that SSRs are preferential markers to use for assessing meadow clonal diversity. Both ISSRs and SSRs detected limited gene flow between Tyrrhenian and Ionian populations.

In order to perform our analysis, we utilized 2 sets of microsatellite (SSR) primers (Procaccini \& Waycott 1998, Alberto et al. 2003) and 8 ISSR primers. Not all the ISSR markers initially screened were utilized for the final analysis. For 2 of them (ISSR1 \& ISSR4) containing (CT) and (GT) repeats, banding patterns were smeared and not easily scorable. Similar patterns could be attributed to high frequency of corresponding microsatellites in the genome (Joshi et al. 2000), although we obtained good results using primers with 


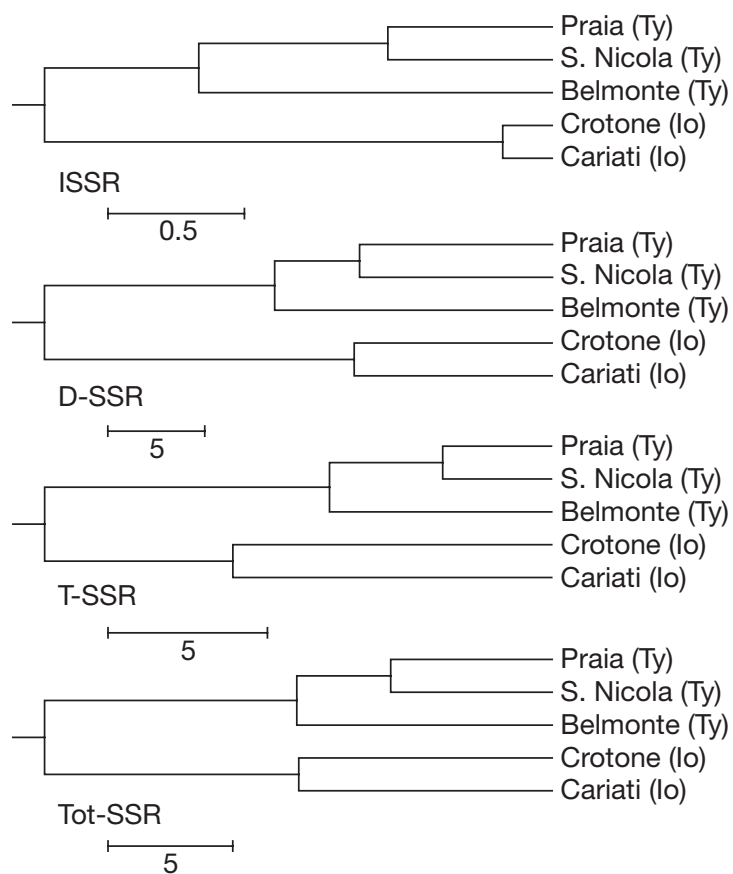

Fig. 4. Representation of UPGMA dendrograms obtained from Nei's (1978) distance values among populations. Ty: Tyrrhenian Sea; Io: Ionian Sea

the same repeats and different 3 '-anchor sites, ISSR2 and ISSR3 respectively. Two other primers, both based on (AT)n repeats (ISSR9 and ISSR12) did not yield any amplification product. It is worth noting that a similar lack of amplification with (AT)-based primers has been observed in other plant species (e.g. Joshi et al. 2000, Kochieva et al. 2002). One possibility is that unsuccessful amplifications could be due to self-complementarities of (AT) repeats, which may self-anneal and form dimers and hairpin loops, hindering amplification (Wang et al. 1998, Cekic et al. 2001).

Arnaud-Haond et al. (2005) compared genetic polymorphism using the same 2 sets of SSR markers utilized here. Their results showed that D-SSR markers were more polymorphic than T-SSRs, allozymes and RAPD markers, in terms of average number of alleles per polymorphic primer/locus. Our data confirm these results, at least with respect to the differences between D-SSRs and T-SSRs, and rank ISSRs close to RAPD markers in terms of the average number of polymorphic bands per primer (Table 2 in this paper; Table 1 in Arnaud-Haond et al. 2005).

We have demonstrated that the efficacy of different marker classes is not homogeneous in terms of their discriminating power $(D)$ and confusion probability $(C)$. One consideration when interpreting the results of $D$ is that this value depends not only on the number of patterns generated, but also on their relative frequency (Tessier et al. 1999). The presence of rare bands/alleles can produce low frequency patterns and result in lower $D$ values. In our study, the best marker combinations for identifying genets would include at least 5 SSR loci (Po5-40, Po-15, Poc-35, Po5-49 and Poc-45) in the 2 less polymorphic populations (Crotone and Cariati). Genetic diversity saturate with a combination of 9 SSR loci (Po5-40, Po-15, Poc-35, Po5-49, Poc-45, Po5, Po5-10, Poc-42 and Poc-5) and 2 ISSR primers (ISSR10 and ISSR2) in the other populations. Comparable estimates made by Arnaud-Haond et al. (2005) reached different conclusions, suggesting that a set of 7 dinucleotides was necessary to saturate genetic diversity independently from population polymorphism. Although it is not surprising that a combination of genetic markers would reveal higher levels of genetic variation than a single set of markers, we conclude that selected ISSR and SSR markers together detect higher levels of polymorphism than either complete set of markers alone. This could be due to the nature of the genetic variation detected by each marker category. SSRs, in fact, detect variation at predeterminate sequence sites, whereas ISSRs quickly and effectively scan the whole genome.

A large difference in ISSR diversity exists between Tyrrhenian and Ionian populations, where this class of markers detected only 3 genotypes. The higher variability in the Tyrrhenian populations detected by SSR markers reflects a general trend where western Mediterranean populations have higher clonal diversity with respect to eastern ones (Procaccini et al. 2002).

The 3 marker sets (ISSRs, T-SSRs and D-SSRs) provide coherent estimates of gene flow, although with different levels of resolution. Tyrrhenian and Ionian populations were always distinct, which indicates an important role of the Calabria peninsula as a biogeographic barrier. AMOVA showed very similar partitioning among individuals within populations, among populations within regions and between regions. Higher variance was always detected within populations, whereas significant genetic structure was detected between populations and regions regardless of the markers considered. This observation contrasts with trends previously suggested, with more polymorphic markers detecting higher levels of differentiation (Peakall et al. 1995, Maguire et al. 2002). In our analysis, the ability of different marker categories to disclose patterns of gene flow was independent of their intrinsic polymorphism.

In conclusion, in our comparative study of ISSR and SSR markers for population genetic analysis of Posidonia oceanica, SSR detected higher levels of clonal diversity than ISSR markers. Nevertheless, we showed that the combined use of selected ISSR and SSR markers increases the values of clonal diversity in the most polymorphic populations. Our analysis detected variable lev- 
els of polymorphism in the populations analyzed, with Tyrrhenian populations always more polymorphic than Ionian ones. Both marker types strongly point at the Calabria peninsula as an important biogeographic barrier between the western and the eastern side of the Mediterranean basin. We suggest that SSR markers should be used for further genetic diversity studies in $P$. oceanica because of their higher polymorphism and statistical power, although ISSRs have the advantage of a technique that is simple, cheap and more accessible for ecology laboratories. The combined use of selected SSR and ISSR markers could represent a convenient approach for identifying genets in clonal plants.

Acknowledgements. We thank Dr. F. S. Rende who provided samples of Posidonia oceanica shoots, W. Kooistra for critical reading of the first version of the manuscript and Fabrizio Campili, Elvira Mauriello and all the staff of the Molecular Biology Service of the Stazione Zoologica for technical support during fragment analyses. Experiments performed in the present paper comply with all relevant Italian laws.

\section{LITERATURE CITED}

Alberto F, Correia L, Arnaud S, Billot C, Duarte CM, Serrao E (2003) New microsatellite markers for the endemic Mediterranean seagrass Posidonia oceanica. Mol Ecol Notes 3: $253-255$

Arnaud-Haond S, Alberto F, Teixeira S, Procaccini G, Serrao E, Duarte CM (2005) Assessing genetic diversity in clonal organisms: low diversity or low resolution? Combining power and cost efficiency in selecting markers. J Hered 96:1-7

Arnaud-Haond S, Migliaccio M, Diaz-Almela E, Teixeira S and 5 others (2007) Vicariance patterns in the Mediterranean Sea: East-West cleavage and low dispersal in the endemic seagrass Posidonia oceanica. J Biogeogr (in press)

Capiomont A, Sandmeier M, Caye G, Meinesz A (1996) Enzyme polymorphism in Posidonia oceanica, a seagrass endemic to the Mediterranean. Aquat Bot 54:265-277

Cekic C, Battey NH, Wilkinson MJ (2001) The potential of ISSR-PCR primer-pair combinations for genetic linkage analysis using the seasonal flowering locus in Fragaria as a model. Theor Appl Genet 103:540-546

Den Hartog C (1970) The seagrasses of the world. North Holland, Amsterdam

Doyle JJ, Doyle JL (1987) A rapid DNA isolation procedure for small quantities of fresh leaf tissue. Phytochem Bull 19: $11-15$

Goldstein DB, Schlotterer C (1999) Microsatellites: Evolution and application. Oxford University Press, Oxford

Goulão L, Oliveira CM (2001) Molecular characterisation of cultivars of apple (Malus $x$ domestica Borkh.) using microsatellite (SSR and ISSR) markers. Euphityca 122: 81-89

Huff DR, Peakall R, Smouse PE (1993) RAPD variation within and among natural populations of outcrossing buffalograss Buchloe dactyloides (Nutt) Engelm. Theor Appl Genet 86:927-934

Jarne P, Lagoda PJL (1996) Microsatellites from molecules to population and back. Trends Ecol Evol 11:424-429
Joshi SP, Gupta VS, Aggarwal RK, Ranjekar PK, Brar DS (2000) Genetic diversity and phylogenetic relationship as revealed by inter simple sequence repeat (ISSR) polymorphism in the genus Oryza. Theor Appl Genet 100: 1311-1320

Jover MA, del Castillo-Agudo L, Garcia-Carrascosa M, Segura J (2003) Random Amplified Polymorphic DNA assessment of diversity in western Mediterranean populations of the seagrass Posidonia oceanica. Am J Bot 90: 364-369

King RA, Gornall RJ, Preston CD, Croft JM (2002) Population differentiation of Potamogeton pectinatus in the Baltic Sea with reference to waterfowl dispersal. Mol Ecol 11: 1947-1956

Kochieva EZ, Ryzhova NN, Khrapalova IA, Pukhalskyi VA (2002) Genetic diversity and phylogenetic relationships in the genus Lycopersicon (Tourn.) Mill. as revealed by intersimple sequence repeat (ISSR) analysis. Russ J Genet 38: 958-966

Maguire TL, Peakall R, Saenger P (2002) Comparative analysis of genetic diversity in the mangrove species Avicennia marina (Forsk.) Vierh. (Avicenniaceae) detected by AFLPs and SSRs. Theor Appl Genet 104:388-398

Micheli C, Paganin P, Peirano A, Caye G, Meinesz A, Bianchi CN (2005) Genetic variability of Posidonia oceanica (L.) Delile in relation to local factors and biogeographic patterns. Aquat Bot 82:210-221

Migliaccio M, De Martino F, Silvestre F, Procaccini G (2005) Meadow-scale genetic structure in Posidonia oceanica. Mar Ecol Prog Ser 304:55-65

Nei M (1978) Estimation of average heterozygosity and genetic distance from a small number of individuals. Genetics 89:583-590

Peakall R, Smouse PE (2006) GENALEX 6: genetic analysis in Excel. Population genetic software for teaching and research. Mol Ecol Notes 6:288-295

Peakall R, Smouse PE, Huff DR (1995) Evolutionary implications of allozyme and RAPD variation in diploid populations of buffalograss Buchloe dactyloides. Mol Ecol 4:135-147

Pleasant JM, Wendel JF (1989) Genetic diversity in a clonal narrow endemic Erythronium propullans and in its widespread progenitor Erythronium albidum. Am J Bot 76: $1136-1151$

Procaccini G, Maltagliati F (2004) Methodological approaches to the analysis of genetic diversity in benthic organisms. In: Gambi MC, Dappiano M (eds) Methods for sampling and study of Mediterranean marine benthos, Vol 11 (suppl). Biologia Marina Mediterranea 11(Suppl):481-519

Procaccini G, Waycott M (1998) Microsatellite loci identified in the seagrass Posidonia oceanica (L.) Delile. J Hered 89: 562-568

Procaccini G, Alberte RS, Mazzella L (1996) Genetic structure of the seagrass Posidonia oceanica in the Western Mediterranean: ecological implications. Mar Ecol Prog Ser 140:153-160

Procaccini G, Orsini L, Ruggiero MV, Scardi M (2001) Spatial patterns of genetic diversity in Posidonia oceanica, an endemic Mediterranean seagrass. Mol Ecol 10:1413-1421

Procaccini G, Ruggiero MV, Orsini L (2002) Genetic structure and distribution of microsatellite population genetic diversity in Posidonia oceanica in the entire Mediterranean basin. Bull Mar Sci 71:1291-1297

Procaccini G, Buia MC, Gambi MC, Perez M, Pergent-Martini C, Pergent G, Romero J (2003) Seagrass status and extent along the Mediterranean coasts of Italy, France and Spain. In: Green EP, Short FT (eds) World atlas of seagrasses. University of California Press, Berkeley, CA, p 48-58 
Reusch TBH (2001) New markers-old questions: population genetics of seagrasses. Mar Ecol Prog Series 211:261-274

Tessier C, David J, This P, Boursiquot JM, Charrier A (1999) Optimization of the choice of molecular markers for varietal identifcation in Vitis vinifera (L.) Theor Appl Genet 98:171-177

Vos P, Hogers R, Bleeker M, Reijans M and 6 others (1995) AFLP: a new technique for DNA fingerprinting. Nucleic Acids Res 23:4407-4414

Wang G, Mahalingam R, Knap HT (1998) (C-A) and (G-A) anchored simple sequence repeats (ASSRs) generated polymorphism in soybean, Glycine max (L.) Merr. Theor Appl Genet 96:1086-1096

Wang CN, Moller M, Cronk QC (2004) Population genetic structure of Titanotrichum oldhamii (Gesneriaceae), a subtropical bulbiliferous plant with mixed sexual and asexual reproduction. Ann Bot (Lond) 93:201-209

Editorial responsibility: Otto Kinne (Editor-in-Chief), Oldendorf/Luhe, Germany
Waycott M, Procaccini G, Les DH, Reusch TBH (2006) Seagrass evolution, ecology and conservation: a genetic perspective. In: Larkum AWD, Orth RJ, Duarte CM (eds) Seagrasses: biology, ecology and conservation. Springer, The Netherlands, p 25-50

Williams JGK, Kubelik AR, Livak KJ, Rafalski JA, Tingey SV (1990) DNA polymorphisms amplified by arbitrary primers useful as genetic markers. Nucleic Acids Res 18: 6531-6535

Yeh FC, Boyle TJB, Yang RC, Ye ZH, Mao JX (1997) POPGENE, the user friendly freeware for population genetic analysis. Molecular Biology and Biotechnology Centre, University of Alberta, Edmonton, Alberta

Zietkiewitcz E, Rafalski A, Labuda D (1994) Genome fingerprinting by simple sequence repeat (SSR)-anchored polymerase chain reaction amplifiction. Genomics 20: 176-183

Submitted: April 20, 2006; Accepted: October 17, 2006 Proofs received from author(s): May 4, 2007 